\title{
Sol-Gel Preparation of Highly Water-Dispersible Silsesquioxane/Zirconium Oxide Hybrid Nanoparticles
}

\author{
Yoshiro Kaneko and Tomoyuki Arake \\ Graduate School of Science and Engineering, Kagoshima University, 1-21-40 Korimoto, Kagoshima 890-0065, Japan \\ Correspondence should be addressed to Yoshiro Kaneko, ykaneko@eng.kagoshima-u.ac.jp
}

Received 18 July 2012; Accepted 27 August 2012

Academic Editor: Kensuke Naka

Copyright ( $) 2012$ Y. Kaneko and T. Arake. This is an open access article distributed under the Creative Commons Attribution License, which permits unrestricted use, distribution, and reproduction in any medium, provided the original work is properly cited.

\begin{abstract}
Highly water-dispersible silsesquioxane/zirconium oxide hybrid nanoparticles ( $\left.\mathrm{SQ} / \mathrm{ZrO}_{2}-\mathrm{NPs}\right)$ were prepared by the following two-step reactions. First, a mixture of 3-aminopropyltrimethoxysilane (APTMOS) and zirconium tetra- $n$-butoxide (ZTB) was stirred in a mixed solvent of $0.1 \mathrm{~mol} / \mathrm{L}$ methanolic hydrochloric acid and $n$-butanol at room temperature, followed by heating in an open system until the solvent was completely evaporated. Then, the aqueous solution obtained by adding water to the resulting product was heated in an open system until the water was completely reevaporated. The products $\left(\mathrm{SQ} / \mathrm{ZrO} \mathrm{O}_{2}-\mathrm{NPs}\right)$ obtained with a feed molar ratio of APTMOS/ZTB of more than 0.3 were dispersed well in water, and their aqueous dispersions were highly transparent, which was confirmed by UV-Vis measurements. In addition, the solid product obtained by drying its aqueous dispersion was redispersed in water. The volume-average particle sizes of $\mathrm{SQ} / \mathrm{ZrO}_{2}-\mathrm{NPs}(\mathrm{APTMOS} / \mathrm{ZTB} \geq 0.3)$ were assessed to be ca. $4.6-23.8 \mathrm{~nm}$ by dynamic light scattering measurements in water. The theoretical refractive index of the $\mathrm{SQ} / \mathrm{ZrO} \mathrm{O}_{2}-\mathrm{NP}$ (APTMOS/ZTB $=0.3$ ) was estimated to be 1.66. It was assumed that the water-dispersible property of the $\mathrm{SQ} / \mathrm{ZrO} 2-\mathrm{NPs}$ probably originated from the $\mathrm{ZrO}_{2}-\mathrm{SiO}_{1.5}\left(\mathrm{CH}_{2}\right)_{3} \mathrm{NH}_{3}{ }^{+} \mathrm{Cl}^{-}$core-shell structures.
\end{abstract}

\section{Introduction}

The dispersion of metal oxide nanoparticles such as those of titanium oxide $\left(\mathrm{TiO}_{2}\right)$ and zirconium oxide $\left(\mathrm{ZrO}_{2}\right)$ is an important topic for their applications, particularly the formation of transparent organic-inorganic hybrid materials with high refractive indices [1-5]. To prepare transparent hybrid materials composed of polymers and metal oxide nanoparticles, metal oxides are required to disperse well (nanoscale) in various media because interface scattering between organic and inorganic components is suppressed in hybrid materials.

Among metal oxide nanoparticles, $\mathrm{ZrO}_{2}$ nanoparticles are attractive because they offer several advantages such as chemical inertness, excellent thermal stability, high refractive index, and high hardness. Although numerous studies have focused on surface modification to disperse $\mathrm{ZrO}_{2}$ nanoparticles, only a few examples regarding the preparation of completely homogeneous dispersions of $\mathrm{ZrO}_{2}$ nanoparticles have been reported [6-8].
On the other hand, we have reported the preparation of water-soluble ammonium cation-containing silsesquioxane (SQ) polymers with regular structures by the sol-gel reaction of 3-aminopropyltrimethoxysilane (APTMOS) under acidic conditions [9-14]. We determined that a salt (ion pair) prepared from an amino group of APTMOS and an acid used as a catalyst probably contributes to the water-solubility and formation of regular structures of the materials. It has also been reported that highly water-dispersible SQ/silica $\left(\mathrm{SiO}_{2}\right)$ hybrid materials have been prepared by the solgel copolycondensation of the mixtures of APTMOS and tetramethoxysilane under the same reaction conditions as those for the aforementioned polySQs [15]. In addition, highly water-dispersible $\mathrm{SQ} / \mathrm{TiO}_{2}$ hybrid nanoparticles were successfully prepared by the following two-step sol-gel copolycondensation under acidic conditions [16]. First, the mixture of APTMOS and titanium tetraisopropoxide was stirred in a mixed solvent of methanolic hydrochloric acid and isopropyl alcohol at room temperature, followed by heating in an open system until the solvent was evaporated. 
Then, the aqueous solution obtained by adding water to the resulting product was heated in an open system until the water was completely reevaporated. The resulting product was dispersed well in water and its aqueous dispersion was highly transparent. These synthetic approaches have motivated us to successfully obtain highly water-dispersible $\mathrm{SQ} / \mathrm{ZrO}_{2}$ hybrid nanoparticles $\left(\mathrm{SQ} / \mathrm{ZrO}_{2}-\mathrm{NPs}\right)$ because the molecular structure of titanium tetraalkoxide as a monomer is similar to that of zirconium tetraalkoxide.

Therefore, in this study, we investigated two-step sol-gel copolycondensations, that is, using alcoholic hydrochloric acid in the first step and water in the second step as solvents, for the mixtures of APTMOS and zirconium tetra- $n$-butoxide (ZTB) under various reaction conditions. As a result, highly water-dispersible $\mathrm{SQ} / \mathrm{ZrO}_{2}-\mathrm{NPs}$ were obtained. This paper reports on the preparation method, water-dispersible behaviors, particle sizes, refractive indices, plausible structures, and formation mechanism of the nanoparticles.

\section{Experimental}

2.1. Materials. All reagents (APTMOS, Tokyo Kasei Kogyo Co., Ltd., Japan and ZTB, Wako Pure Chemical Industries, Ltd., Japan $)$ and solvents $(0.5 \mathrm{~mol} / \mathrm{L}$ methanolic hydrochloric acid and $n$-butanol, Wako Pure Chemical Industries, Ltd., Japan) of reagent-grade quality were commercially purchased and used without further purification.

2.2. Preparation of Highly Water-Dispersible $\mathrm{SQ} / \mathrm{ZrO}_{2}-\mathrm{NPs}$. A typical experiment for the preparation of highly waterdispersible $\mathrm{SQ} / \mathrm{ZrO}_{2}-\mathrm{NPs}$ was conducted according to the following procedure. After $0.1 \mathrm{~mol} / \mathrm{L}$ methanolic hydrochloric acid $(62.5 \mathrm{~mL}=6.25 \mathrm{mmol})$ was added to APTMOS $(0.269 \mathrm{~g}=1.5 \mathrm{mmol})$, the solution was added to a solution of ZTB ( $85 \mathrm{wt} \% n$-butanol solution) $(2.257 \mathrm{~g}=5.0 \mathrm{mmol})$ in $n$-butanol $(125 \mathrm{~mL})$. The mixture was stirred for $2 \mathrm{~h}$ at room temperature, followed by heating at ca. $50^{\circ} \mathrm{C}$ in an open system until the solvent was evaporated and further heating at $100^{\circ} \mathrm{C}$ for $30 \mathrm{~min}$ to completely remove the solvent. The obtained product was dissolved in water $(100 \mathrm{~mL})$ and the solution was heated at ca. $50^{\circ} \mathrm{C}$ in the open system until the water was reevaporated. The product was left at $100^{\circ} \mathrm{C}$ for $30 \mathrm{~min}$ and was then dispersed in water $(100 \mathrm{~mL})$ by stirring at room temperature for $12 \mathrm{~h}$. After the resulting aqueous dispersion was filtrated to remove a slightly insoluble residue, it was heated at $50^{\circ} \mathrm{C}$ in an open system to evaporate water and was further heated at $100^{\circ} \mathrm{C}$ for $30 \mathrm{~min}$ to yield ca. $1.033 \mathrm{~g}$ of a glassy white product $\left(\mathrm{SQ} / \mathrm{ZrO}_{2}-\mathrm{NPs}\right)$.

2.3. Ion-Exchange Reaction of $\mathrm{SQ} / \mathrm{ZrO}_{2}-\mathrm{NP}$ with Sodium Laurate. SQ/ZrO ${ }_{2}-\mathrm{NP}$ (elemental ratio of $\mathrm{Si} / \mathrm{Zr}=0.34$, $0.173 \mathrm{~g}=0.34 \mathrm{mmol}$ of the amino group) was dispersed in $20 \mathrm{~mL}$ of water. This aqueous dispersion was poured into a sodium laurate aqueous solution $(0.1 \mathrm{~mol} / \mathrm{L}, 10 \mathrm{~mL})$ to precipitate the product. The precipitate was collected by filtration, washed with water, and dried under reduced
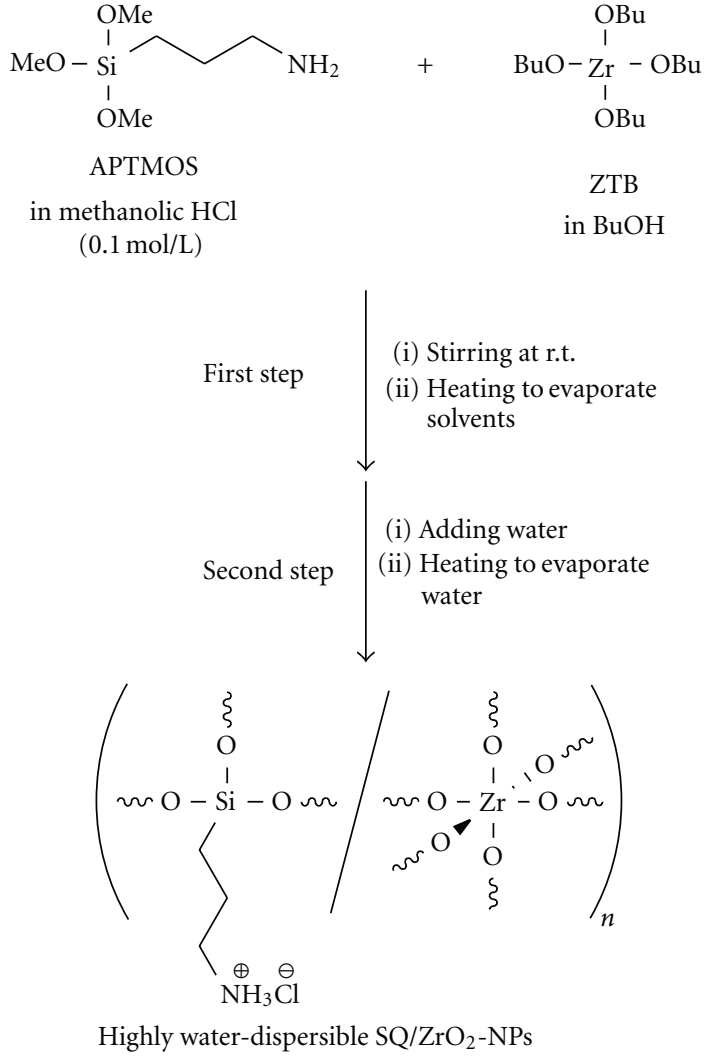

Scheme 1: Preparation of highly water-dispersible $\mathrm{SQ} / \mathrm{ZrO}_{2}-\mathrm{NPs}$.

pressure at room temperature to yield ca. $0.252 \mathrm{~g}$ of a white powdered product.

2.4. Measurements. Elemental ratios of $\mathrm{Si} / \mathrm{Zr}$ in the $\mathrm{SQ} / \mathrm{ZrO}_{2}-\mathrm{NPs}$ were estimated by energy-dispersive X-ray (EDX) spectroscopy using an XL30 scanning electron microscope (FEI Company). The UV-Vis spectra of the aqueous dispersions of the $\mathrm{SQ} / \mathrm{ZrO}_{2}-\mathrm{NPs}$ were recorded using a Jasco V-650 spectrophotometer (JASCO Corporation, Japan). A quartz cell (thickness $10 \mathrm{~mm}$ ) containing water was used as a reference for UV-Vis measurements. The particle sizes of the SQ/ZrO $\mathrm{Zr}_{2}-\mathrm{NPs}$ were measured in water at $25^{\circ} \mathrm{C}$ using a Zetasizer Nano ZS (dynamic light scattering (DLS) apparatus) (Malvern Instruments, UK). The refractive indices of the aqueous dispersions of the $\mathrm{SQ} / \mathrm{ZrO}_{2}-\mathrm{NPs}$ were determined at $25^{\circ} \mathrm{C}$ using an $\mathrm{RX}-5000 \alpha$ refractometer (Atago Co., Ltd., Japan). The measurement wavelength was $589.3 \mathrm{~nm}$ (Na-D line).

\section{Results and Discussion}

3.1. Preparation of Highly Water-Dispersible $\mathrm{SQ} / \mathrm{ZrO}_{2}-\mathrm{NPs}$. In the first step, intermediates were prepared by stirring the mixtures of APTMOS and ZTB (feed molar ratio = $0-1.0: 1.0)$ in a mixed solvent of $0.1 \mathrm{~mol} / \mathrm{L}$ methanolic hydrochloric acid and $n$-butanol at room temperature, followed by heating in an open system until the solvent was evaporated (Scheme 1). In the second step, after water 
TABLE 1: Feed molar ratios of APTMOS/ZTB and elemental ratios of $\mathrm{Si} / \mathrm{Zr}$ in $\mathrm{SQ} / \mathrm{ZrO}_{2}-\mathrm{NPs}$.

\begin{tabular}{lcc}
\hline Run & $\begin{array}{c}\text { Feed molar ratio } \\
(\text { APTMOS/ZTB })\end{array}$ & $\begin{array}{c}\text { Elemental ratio in } \\
\mathrm{SQ} / \mathrm{ZrO}_{2}-\mathrm{NPs}^{(\mathrm{a})}(\mathrm{Si} / \mathrm{Zr})\end{array}$ \\
\hline 1 & 1.0 & 1.10 \\
2 & 0.8 & 0.99 \\
3 & 0.6 & 0.79 \\
4 & 0.3 & 0.34 \\
5 & 0.2 & 0.29 \\
6 & 0.1 & 0.22 \\
${ }^{(\mathrm{a})}$ Estimated by EDX measurements.
\end{tabular}

was added to the resulting intermediates, these aqueous solutions were also heated in an open system until the water was completely reevaporated to obtain $\mathrm{SQ} / \mathrm{ZrO}_{2}$ NPs (Scheme 1). These materials were almost quantitatively obtained by this reaction system.

The values of Si/Zr elemental ratios in the $\mathrm{SQ} / \mathrm{ZrO}_{2}-\mathrm{NPs}$ estimated by EDX measurements are listed in Table 1. These results indicate that the $\mathrm{Si} / \mathrm{Zr}$ elemental ratios were almost consistent with the feed molar ratio of APTMOS to ZTB in all cases.

3.2. Water-Dispersibility of $\mathrm{SQ} / \mathrm{ZrO}_{2}-\mathrm{NPs}$. The transmittances of the $1.0 \mathrm{w} / \mathrm{v} \%$ aqueous dispersions of the $\mathrm{SQ} / \mathrm{ZrO}_{2}-\mathrm{NPs}$ obtained with various feed molar ratios of APTMOS/ZTB were measured by UV-Vis spectroscopy (Figure 1). For the aqueous dispersions of the $\mathrm{SQ} / \mathrm{ZrO}_{2}-\mathrm{NPs}$ obtained with a feed molar ratio of APTMOS/ZTB greater than 0.3 , high transmittances were observed in the visible wavelength region $(>95 \%$, transmitted light $>380 \mathrm{~nm})$, indicating that the $\mathrm{SQ} / \mathrm{ZrO}_{2}$-NPs $(\mathrm{APTMOS} / \mathrm{ZTB} \geq 0.3$ ) dispersed well in water and the resulting aqueous dispersions were highly transparent (Figure 1). The photographs of the aqueous dispersions also support their transparencies (Figures 2(a) and 2(b)). These high transparencies of the aqueous dispersions did not change, and precipitates were not generated even after standing for several weeks, indicating that the $\mathrm{SQ} / \mathrm{ZrO}_{2}-\mathrm{NPs}(\mathrm{APTMOS} / \mathrm{ZTB} \geq 0.3$ ) were stably maintained in water without aggregation.

On the other hand, the transmittance of the aqueous dispersion of the $\mathrm{SQ} / \mathrm{ZrO}_{2}-\mathrm{NP}(\mathrm{APTMOS} / \mathrm{ZTB}=0.2$, concentration $=1.0 \mathrm{w} / \mathrm{v} \%$ ) was lower than those of the aforementioned nanoparticles (Figure 1). In addition, those of $\mathrm{SQ} / \mathrm{ZrO}_{2}$-NPs $($ APTMOS/ZTB $\leq 0.1$, concentration $=1.0$ $\mathrm{w} / \mathrm{v} \%$ ) were considerably low, indicating that these products did not disperse well in water (Figure 1). Their turbidities were also confirmed by visual observation (Figures 2(d) and $2(\mathrm{e}))$. On the basis of the aforementioned results, the products were found to be highly dispersed in water with ca. $75 \mathrm{~mol} \%$ incorporation of the $\mathrm{ZrO}_{2}$ component. In the case of the SQ/ZrO ${ }_{2}$-NPs (APTMOS/ZTB $\leq 0.2$ ), the compositional ratio of the $\mathrm{SiO}_{1.5}\left(\mathrm{CH}_{2}\right)_{3} \mathrm{NH}_{3}{ }^{+} \mathrm{Cl}^{-}$components was relatively low. Therefore, it is assumed that the

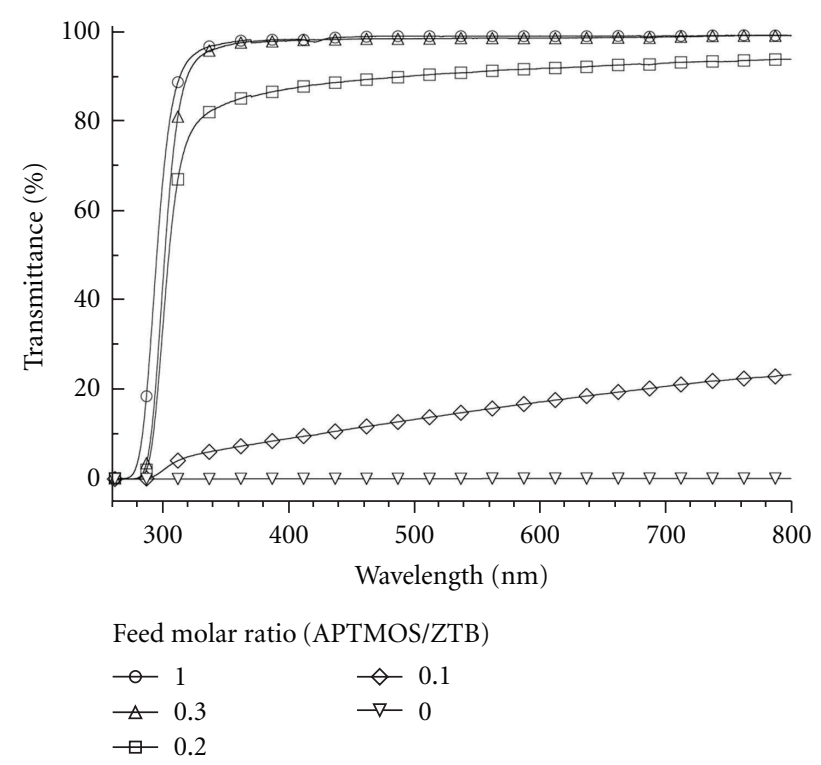

Figure 1: UV-Vis spectra of aqueous dispersions $(1.0 \mathrm{w} / \mathrm{v} \%)$ of $\mathrm{SQ} / \mathrm{ZrO}_{2}-\mathrm{NPs}$ obtained with various feed molar ratios.

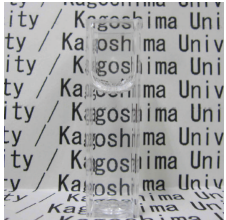

(a)

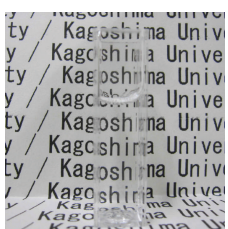

(c)

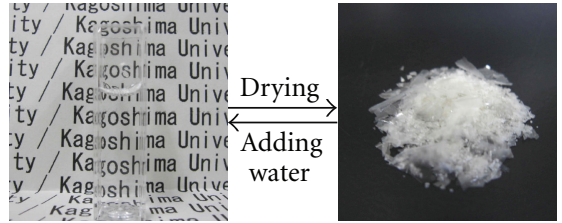

(b)

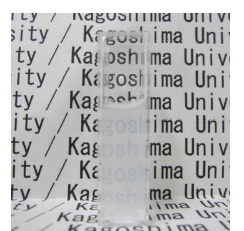

(d) (f)

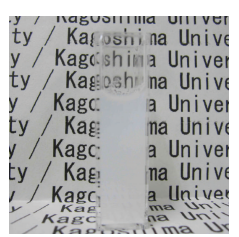

(e)
FIgURE 2: Photographs of aqueous dispersions $(1.0 \mathrm{w} / \mathrm{v} \%)$ of $\mathrm{SQ} / \mathrm{ZrO}_{2}$-NPs obtained with various feed molar ratios for APTMOS/ZTB: (a) 1.0, (b) 0.3, (c) 0.2, (d), 0.1, and (e) 0 and (f) solid state of $\mathrm{SQ} / \mathrm{ZrO}_{2}-\mathrm{NP}$ (feed molar ratio of APTMOS/ZTB $=0.3$ ).

$\mathrm{SiO}_{1.5}\left(\mathrm{CH}_{2}\right)_{3} \mathrm{NH}_{3}{ }^{+} \mathrm{Cl}^{-}$components, which play an important role in high water-dispersibility, could not completely cover the nanoparticle surface.

The transmittances of the aqueous dispersions of the $\mathrm{SQ} / \mathrm{ZrO}_{2}-\mathrm{NPs}(\mathrm{APTMOS} / \mathrm{ZTB}=0.3$ ) with various concentrations were investigated through UV-Vis measurements (Figure 3). For the aqueous dispersions up to $5.0 \mathrm{w} / \mathrm{v} \%$, relatively higher transmittances were observed ( $>90 \%$, transmitted light $>380 \mathrm{~nm}$ ).

A solid product was recovered by the evaporation of the aforementioned aqueous dispersion (Figure 2(f), e.g., $\mathrm{SQ} / \mathrm{ZrO}_{2}-\mathrm{NPs}(\mathrm{APTMOS} / \mathrm{ZTB}=0.3)$ ), indicating that the product's water-dispersibility is not due to the decomposition of $\mathrm{Zr}-\mathrm{O}$ and $\mathrm{Si}-\mathrm{O}$ bonds. Even after repeating the treatment of dispersion in water and the evaporation 


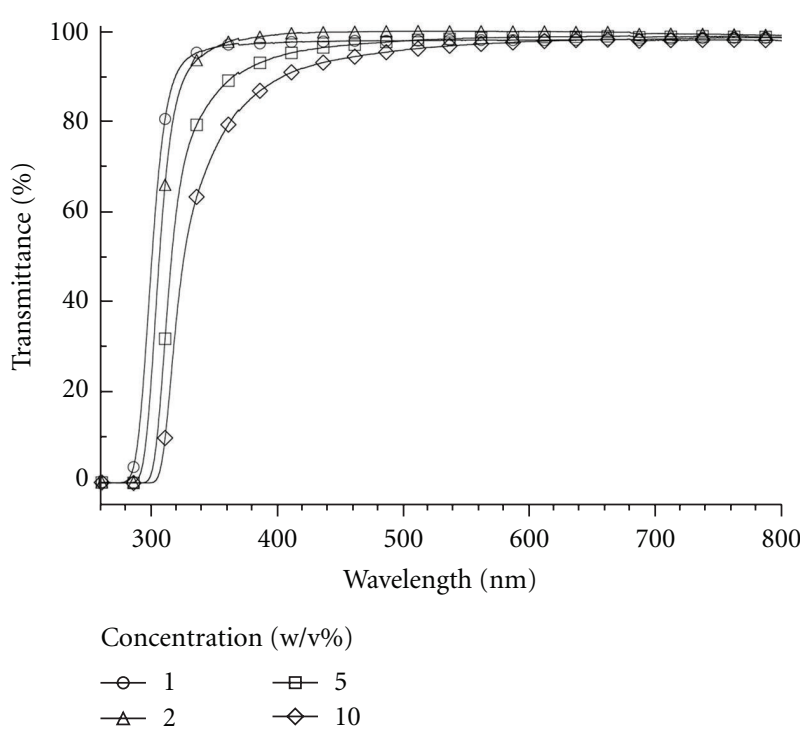

FIgURE 3: UV-Vis spectra of aqueous dispersions of $\mathrm{SQ} / \mathrm{ZrO}_{2}$ $\mathrm{NPs}$ (feed molar ratio of APTMOS/ZTB $=0.3$ ) with various concentrations.

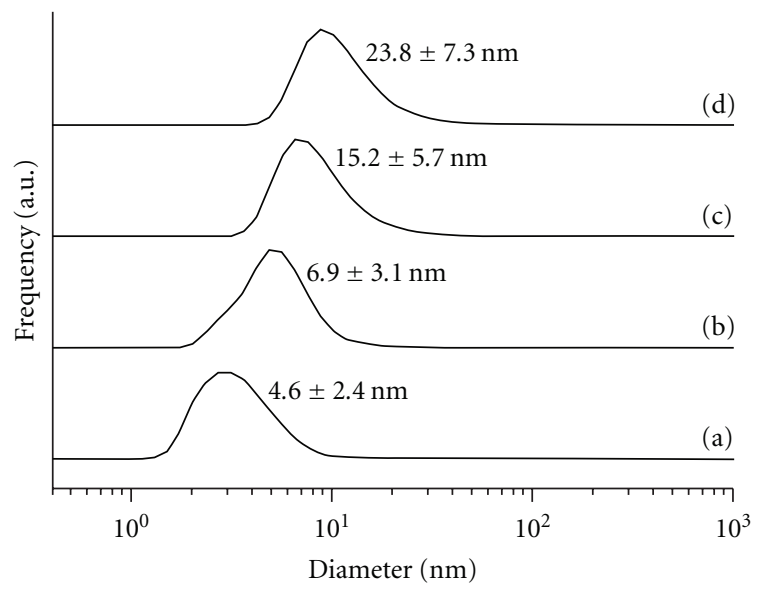

Figure 4: Volume-average particle size distributions of $2.0 \mathrm{w} / \mathrm{v} \%$ aqueous dispersions of SQ/Z $\mathrm{ZrO}_{2}-\mathrm{NPs}$ measured by DLS at $25^{\circ} \mathrm{C}$. Feed molar ratio of APTMOS/ZTB $=$ (a) 0.3 , (b) 0.6 , (c) 0.8 , and (d) 1.0.

of water three times, the high transparency of the aqueous dispersion of the $\mathrm{SQ} / \mathrm{ZrO}_{2}-\mathrm{NP}$ was maintained, as confirmed by visual observation. Here, the dispersion treatment was performed by adding water to the $\mathrm{SQ} / \mathrm{ZrO}_{2}-\mathrm{NP}$ (concentration, $1.0 \mathrm{w} / \mathrm{v} \%$ ) and stirring at ca. $50^{\circ} \mathrm{C}$. These results strongly indicate that $\mathrm{SQ} / \mathrm{ZrO}_{2}-\mathrm{NPs}$ exhibit high waterdispersibility and redispersion is possible.

The volume-average particle sizes of the SQ/ZrO $\mathrm{rO}_{2}-\mathrm{NPs}$ (APTMOS/ZTB $=0.3,0.6,0.8$, and 1.0 ) estimated by DLS measurements in water $(2.0 \mathrm{w} / \mathrm{v} \%)$ at $25^{\circ} \mathrm{C}$ were assessed to be $4.6 \pm 2.4,6.9 \pm 3.1,15.2 \pm 5.7$, and $23.8 \pm 7.3 \mathrm{~nm}$, respectively (Figure 4), indicating that the $\mathrm{SQ} / \mathrm{ZrO}_{2}-\mathrm{NPs}$ (APTMOS/ZTB $\geq 0.3$ ) were well-dispersed, relatively small nanoparticles.

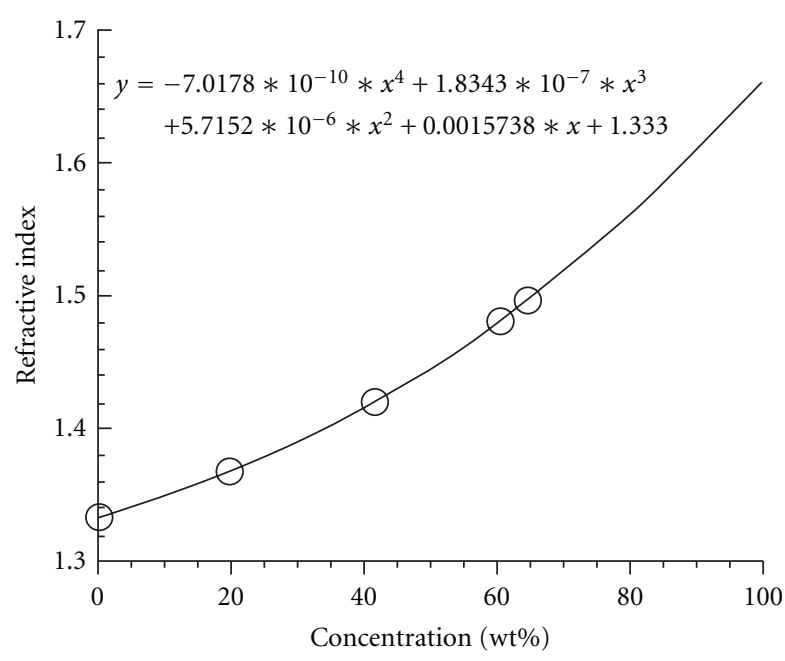

Figure 5: Correlation between refractive indices and concentrations of aqueous dispersions of $\mathrm{SQ} / \mathrm{ZrO}_{2}-\mathrm{NPs}$ (feed molar ratio of $\mathrm{APTMOS} / \mathrm{ZTB}=0.3$ ).

3.3. Refractive Indices of $\mathrm{SQ} / \mathrm{ZrO}_{2}-\mathrm{NP}$ Aqueous Dispersions. To estimate the refractive indices of the SQ/Z $\mathrm{ZO}_{2}-\mathrm{NP}$ (APT$\mathrm{MOS} / \mathrm{ZTB}=0.3$ ) by the Abb refractometer, we attempted to prepare a film on a flat glass substrate. However, a stable film could not be obtained. Therefore, various concentrations (0 (only water), $19.6,41.7,60.6$, and $64.7 \mathrm{wt} \%$ ) of the aqueous dispersions of the $\mathrm{SQ} / \mathrm{ZrO}_{2}-\mathrm{NP}$ were prepared, and the refractive indices of these dispersions were estimated by the Abb refractometer to be $1.333,1.367,1.420,1.481$, and 1.496 , respectively. These values were plotted on a graph and their fitted curve was calculated as follows: $[y=-7.0178$ $\times 10^{-10} x^{4}+1.8343 \times 10^{-7} x^{3}+5.7152 \times 10^{-6} x^{2}+1.5738$ $\left.\times 10^{-3} x+1.333\right] ; y$ and $x$ denote refractive indices and concentrations of the aqueous dispersions of the $\mathrm{SQ} / \mathrm{ZrO}_{2}$ $\mathrm{NP}(\mathrm{APTMOS} / \mathrm{ZTB}=0.3)$, respectively (Figure 5$)$. From this fitted curve, the theoretical refractive index of the $\mathrm{SQ} / \mathrm{ZrO}_{2}$ $\mathrm{NP}$, that is, that for $100 \mathrm{wt} \%$, was calculated to be 1.66 .

3.4. Investigation of Necessity of Two-Step Sol-Gel Copolycondensation. The highly water-dispersible $\mathrm{SQ} / \mathrm{ZrO}_{2}-\mathrm{NPs}$ were obtained by the aforementioned two-step sol-gel copolycondensation; that is, alcoholic hydrochloric acid in the first step and water in the second step were employed as solvents. Here, to investigate the necessity of this two-step reaction, a comparative sol-gel copolycondensation experiment was performed using $0.1 \mathrm{~mol} / \mathrm{L}$ aqueous hydrochloric acid as a substitute for methanolic hydrochloric acid in the first step. The Si/Zr elemental ratio of the resulting product obtained with a feed molar ratio of APTMOS/ZTB $=0.3$ was estimated by EDX measurements to be ca. 0.38. The transmittance of the aqueous dispersion of this product decreased compared with that of the $\mathrm{SQ} / \mathrm{ZrO}_{2}-\mathrm{NPs}$ obtained by the aforementioned two-step sol-gel copolycondensation (Figure 6). Its turbidity was also confirmed by visual observation (Figure 6, inset). Use of aqueous hydrochloric acid in the first step probably resulted in the formation of 


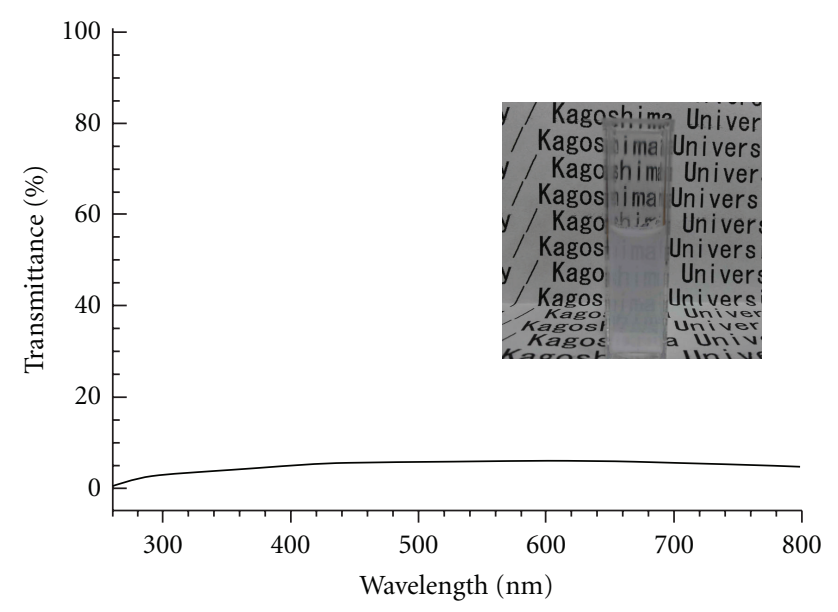

FIgURE 6: UV-Vis spectrum of aqueous dispersion $(1.0 \mathrm{w} / \mathrm{v} \%)$ of the product obtained using $0.1 \mathrm{~mol} / \mathrm{L}$ aqueous hydrochloric acid as a substitute for methanolic hydrochloric acid in the first-step reaction. The inset shows a photograph of this aqueous dispersion.

a larger particle size because the progress of the sol-gel reaction of ZTB was considerably faster than that using methanolic hydrochloric acid. These results indicate that the two-step reaction is required for the preparation of highly water-dispersible nanoparticles.

3.5. Plausible Structure of $S Q / Z \mathrm{ZO}_{2}-\mathrm{NPS}$. We assume that the water-dispersible properties of the $\mathrm{SQ} / \mathrm{ZrO}_{2}-\mathrm{NPs}$ originated from the $\mathrm{ZrO}_{2}-\mathrm{SiO}_{1.5}\left(\mathrm{CH}_{2}\right) \mathrm{NH}_{3}{ }^{+} \mathrm{Cl}^{-}$core-shell structure. Therefore, to investigate the presence of ammonium cations $\left(-\mathrm{NH}_{3}{ }^{+}\right)$on the surface of the $\mathrm{SQ} / \mathrm{ZrO}_{2}-\mathrm{NPs}$, an ionexchange reaction of the $\mathrm{SQ} / \mathrm{ZrO}_{2}-\mathrm{NP}$ (APTMOS/ZTB = 0.3 ) was performed with sodium laurate. This was achieved by pouring the $\mathrm{SQ} / \mathrm{ZrO}_{2}-\mathrm{NP}$ aqueous dispersion into an aqueous solution of sodium laurate to immediately precipitate. The resulting product was not dispersed in water due to its hydrophobicity (Figure 7), although, as previously described, that with $\mathrm{Cl}^{-}$was well dispersed. These results indicate the possibility of the ion-exchange reaction of the $\mathrm{SQ} / \mathrm{ZrO}_{2}-\mathrm{NP}$, resulting in change in dispersibility in water due to the exchange of counter anions (from $\mathrm{Cl}^{-}$to a laurate anion). Therefore, the $\mathrm{SQ} / \mathrm{ZrO}_{2}-\mathrm{NP}$ probably exhibits a coreshell structure with $-\mathrm{NH}_{3}{ }^{+}$on its surface. Owing to charge repulsion of $-\mathrm{NH}_{3}{ }^{+}$groups on the surface, $\mathrm{SQ} / \mathrm{ZrO}_{2}-\mathrm{NPs}$ were dispersed well in water.

3.6. Plausible Formation Mechanism of $\mathrm{SQ} / \mathrm{ZrO}_{2}-\mathrm{NPs}$ with Core-Shell Structures. Since ZTB is much easier to be hydrolyzed than APTMOS, a nanoaggregate composed of ZTB and oligomeric $\mathrm{ZrO}_{2}$ components would form in the first place. Successively, hydrolysis of less reactive APTMOS probably occurred, and partially hydrolyzed material composed of $\left(\mathrm{CH}_{3} \mathrm{O}\right)_{3} \mathrm{Si}\left(\mathrm{CH}_{2}\right)_{3} \mathrm{NH}_{3}{ }^{+} \mathrm{Cl}^{-}$and oligomeric $\mathrm{SiO}_{1.5}\left(\mathrm{CH}_{2}\right)_{3} \mathrm{NH}_{3}{ }^{+} \mathrm{Cl}^{-}$components would stack on the surface of the $\mathrm{ZTB} / \mathrm{ZrO}_{2}$ aggregate. Thus, it would be assumed that the intermediate with the core-shell structure was formed (Scheme 2(a)). Subsequently, when the water was

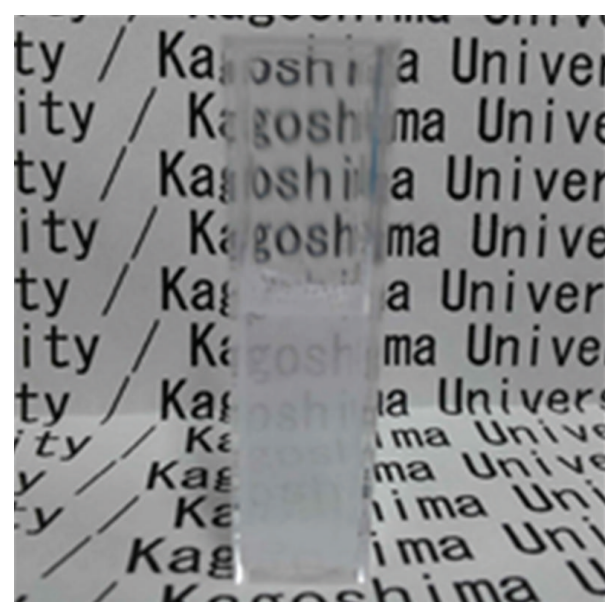

FIGURE 7: A photograph of aqueous suspension (1.0 w/v\%) of the product obtained by ion-exchange reaction of the $\mathrm{SQ} / \mathrm{ZrO}_{2}-\mathrm{NP}$ (feed molar ratio of APTMOS/ZTB $=0.3$ ) with sodium laurate.

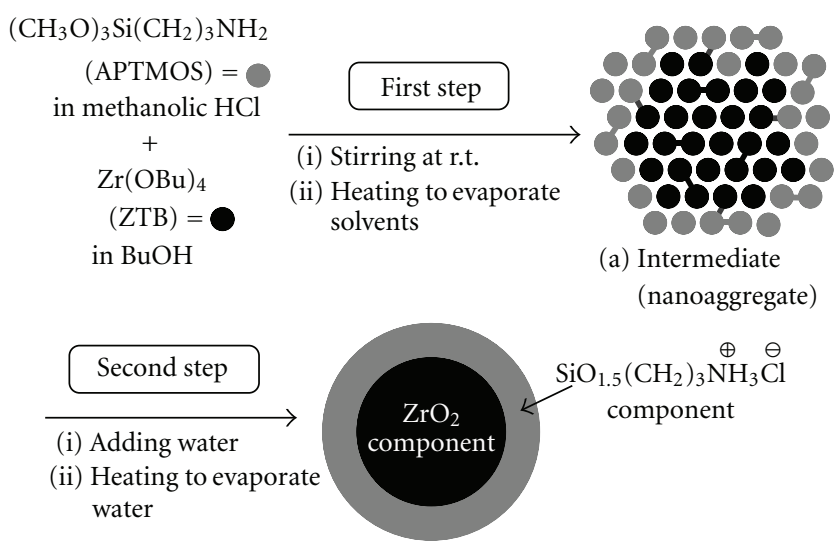

(b) Highly water-dispersible $\mathrm{SQ} / \mathrm{ZrO}_{2}-\mathrm{NPs}$ with core-shell structures

Scheme 2: Plausible formation mechanism of SQ/ $\mathrm{ZrO}_{2}-\mathrm{NPs}$ with core-shell structures.

added to the intermediate and the resulting aqueous solution was heated in the open system, the reaction completely proceeded to probably prepare the final product $\left(\mathrm{SQ} / \mathrm{ZrO}_{2}-\right.$ $\mathrm{NPs}$ ) with $\mathrm{ZrO}_{2}-\mathrm{SiO}_{1.5}\left(\mathrm{CH}_{2}\right)_{3} \mathrm{NH}_{3}{ }^{+} \mathrm{Cl}^{-}$core-shell structure (Scheme 2(b)).

\section{Conclusions}

Highly water-dispersible $\mathrm{SQ} / \mathrm{ZrO}_{2}-\mathrm{NPs}$ were prepared by the two-step sol-gel copolycondensation of a mixture of APTMOS and ZTB, whereby $n$-butanol and methanolic hydrochloric acid were first used as a mixed solvent, followed by water. Aqueous dispersions of $\mathrm{SQ} / \mathrm{ZrO}_{2}-\mathrm{NPs}$ obtained with a feed molar ratio of APTMOS/ZTB of more than 0.3 were highly transparent, and redispersion was possible. The volume-average particle sizes of the $\mathrm{SQ} / \mathrm{ZrO}_{2}-\mathrm{NPs}$ (APTMOS/ZTB $\geq 0.3$ ) were assessed to be ca. $4.6-23.8 \mathrm{~nm}$ 
by DLS measurements in water. The theoretical refractive index of the SQ/ZrO $\mathrm{ZO}_{2}$-NP (APTMOS/ZTB = 0.3) was estimated to be 1.66. It was assumed that the water-dispersible properties of the SQ/ZrO 2 -NPs originated from the $\mathrm{ZrO}_{2}$ $\mathrm{SiO}_{1.5}\left(\mathrm{CH}_{2}\right)_{3} \mathrm{NH}_{3}{ }^{+} \mathrm{Cl}^{-}$core-shell structure.

\section{Acknowledgments}

The authors thank Professor Y. Suda and Dr. M. Wakao of Graduate School of Science and Engineering, Kagoshima University (Japan), for support in DLS measurements. They also acknowledge Professor M. Higo and Dr. M. Mitsushio of Graduate School of Science and Engineering, Kagoshima University (Japan), for refractive index measurements.

\section{References}

[1] S. Lee, H. J. Shin, S. M. Yoon, D. K. Yi, J. Y. Choi, and U. Paik, "Refractive index engineering of transparent $\mathrm{ZrO}_{2}$ polydimethylsiloxane nanocomposites," Journal of Materials Chemistry, vol. 18, no. 15, pp. 1751-1755, 2008.

[2] T. Otsuka and Y. Chujo, "Preparation and characterization of poly(vinylpyrrolidone)/Zirconium oxide hybrids by using inorganic nanocrystals," Polymer Journal, vol. 40, no. 12, pp. 1157-1163, 2008.

[3] T. Otsuka and Y. Chujo, "Synthesis of transparent poly (vinylidene fluoride) (PVdF)/zirconium oxide hybrids without crystallization of PVdF chains," Polymer, vol. 50, no. 14, pp. 3174-3181, 2009.

[4] M. Ochi, D. Nii, and M. Harada, "Effect of acetic acid content on in situ preparation of epoxy/zirconia hybrid materials," Journal of Materials Science, vol. 45, no. 22, pp. 6159-6165, 2010.

[5] Y. Hu, G. Gu, S. Zhou, and L. Wu, "Preparation and properties of transparent $\mathrm{PMMA} / \mathrm{ZrO}_{2}$ nanocomposites using 2-hydroxyethyl methacrylate as a coupling agent," Polymer, vol. 52, no. 1, pp. 122-129, 2011.

[6] M. Chatry, M. Henry, and J. Livage, "Synthesis of nonaggregated nanometric crystalline zirconia particles," Materials Research Bulletin, vol. 29, no. 5, pp. 517-522, 1994.

[7] J. Joo, T. Yu, Y. W. Kim et al., "Multigram scale synthesis and characterization of monodisperse tetragonal zirconia nanocrystals," Journal of the American Chemical Society, vol. 125, no. 21, pp. 6553-6557, 2003.

[8] W. He, Z. Guo, Y. Pu, L. Yan, and W. Si, "Polymer coating on the surface of zirconia nanoparticles by inductively coupled plasma polymerization," Applied Physics Letters, vol. 85, no. 6, pp. 896-898, 2004.

[9] Y. Kaneko, N. Iyi, K. Kurashima, T. Matsumoto, T. Fujita, and K. Kitamura, "Hexagonal-structured polysiloxane material prepared by sol-gel reaction of aminoalkyltrialkoxysilane without using surfactants," Chemistry of Materials, vol. 16, no. 18, pp. 3417-3423, 2004.

[10] Y. Kaneko, N. Iyi, T. Matsumoto, and K. Kitamura, "Synthesis of rodlike polysiloxane with hexagonal phase by sol-gel reaction of organotrialkoxysilane monomer containing two amino groups," Polymer, vol. 46, no. 6, pp. 1828-1833, 2005.

[11] Y. Kaneko and N. Iyi, "Sol-gel synthesis of rodlike polysilsesquioxanes forming regular higher-ordered nanostructure," Zeitschrift für Kristallographie, vol. 222, no. 11, pp. 656-662, 2007.
[12] Y. Kaneko and N. Iyi, "Sol-gel synthesis of water-soluble polysilsesquloxanes with regular structures," Kobunshi Ronbunshu, vol. 67, no. 5, pp. 280-287, 2010.

[13] Y. Kaneko, M. Shoiriki, and T. Mizumo, "Preparation of cagelike octa(3-aminopropyl)silsesquioxane trifluoromethanesulfonate in higher yield with a shorter reaction time," Journal of Materials Chemistry, vol. 22, no. 29, pp. 14475-14478, 2012.

[14] Y. Kaneko, H. Toyodome, M. Shoiriki, and N. Iyi, "Preparation of ionic silsesquioxanes with regular structures and their hybridization," International Journal of Polymer Science. In press.

[15] Y. Kaneko, N. Iyi, T. Matsumoto, and H. Usami, "Synthesis of water-soluble silicon oxide material by sol-gel reaction in tetraalkoxysilane-aminoalkyltrialkoxysilane binary system," Journal of Materials Research, vol. 20, no. 8, pp. 2199-2204, 2005.

[16] Y. Kaneko, "Preparation of highly water-dispersible titaniumsilicon binary oxide materials by sol-gel method," Journal of Nanoscience and Nanotechnology, vol. 11, no. 3, pp. 2458-2464, 2011. 

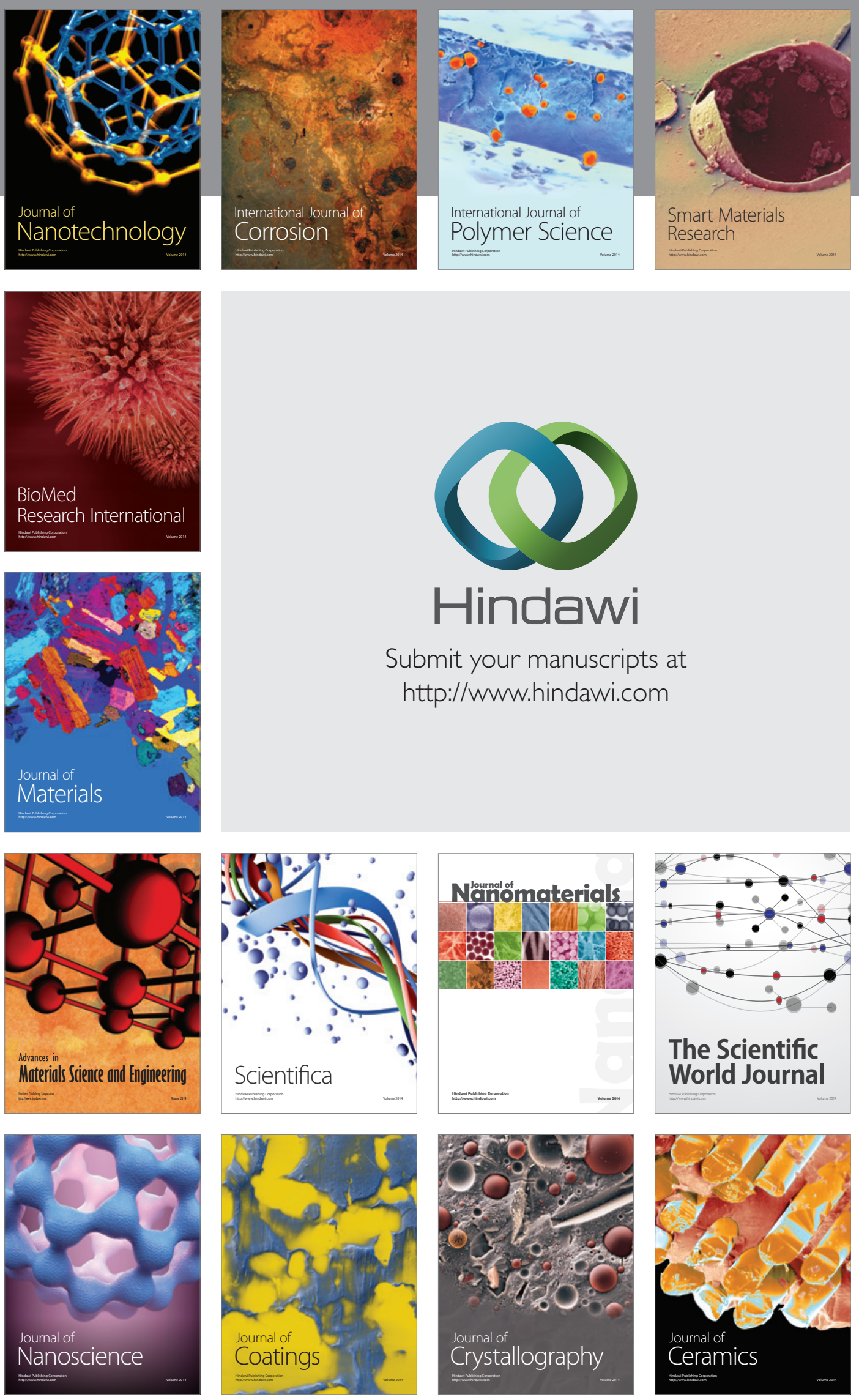

The Scientific World Journal

Submit your manuscripts at

http://www.hindawi.com

\section{World Journal}

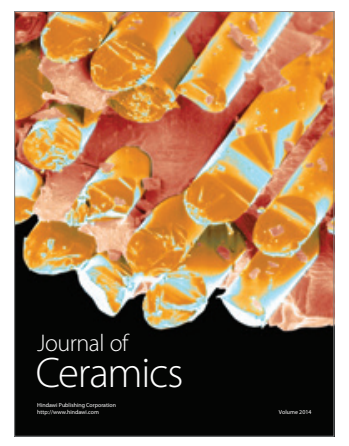

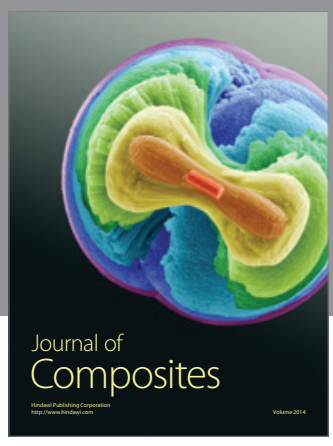
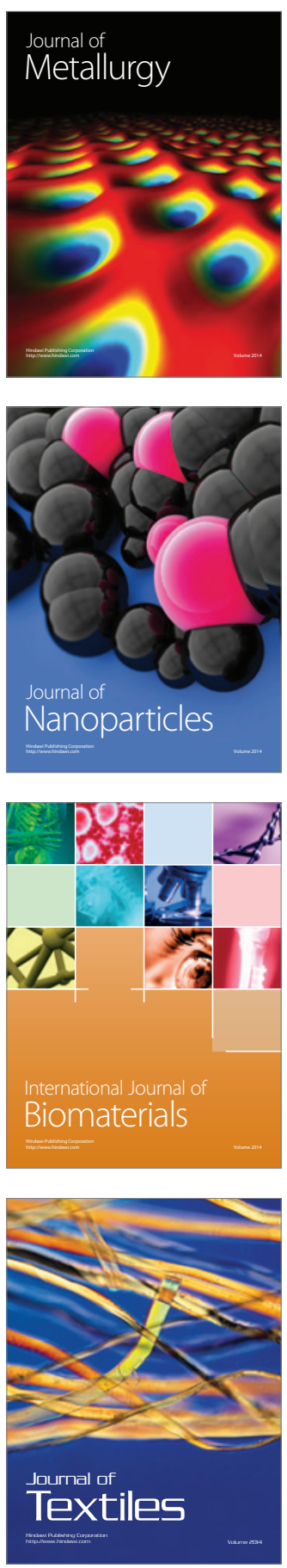